American Journal of Educational Research and Reviews
(ISSN:2474-9265)

\title{
Departmentalization in Elementary Schools: Contradictions Teachers Confront
}

\author{
Richard L. Allington \\ University of Tennessee.
}

\begin{abstract}
This paper presents analyses of observational and interview data gathered in a study of exemplary fourth-grade teachers from five states. The central issue explored is the relative merits of self-contained and departmentalized models of instruction. We found no achievement differences in the classrooms by organizational pattern, but differences in the instruction offered in these two models were identified, and mixed views of the relative advantages of either organization plan were expressed by the participants. A key tension was whether these organizational plans are intended to primarily benefit teachers or students. However, the complexities of the cost/benefit concerns are the findings that this study highlights.
\end{abstract}

Keywords: Contradictions Teachers Confront; Departmentalization
*Correspondence to Author:

Richard L. Allington

University of Tennessee.

Tel: 518-421-1775

How to cite this article:

Richard L. Allington. Departmentalization in Elementary Schools: Contradictions Teachers Confront. American Journal of Educational Research and Reviews, 2020; 5:77.

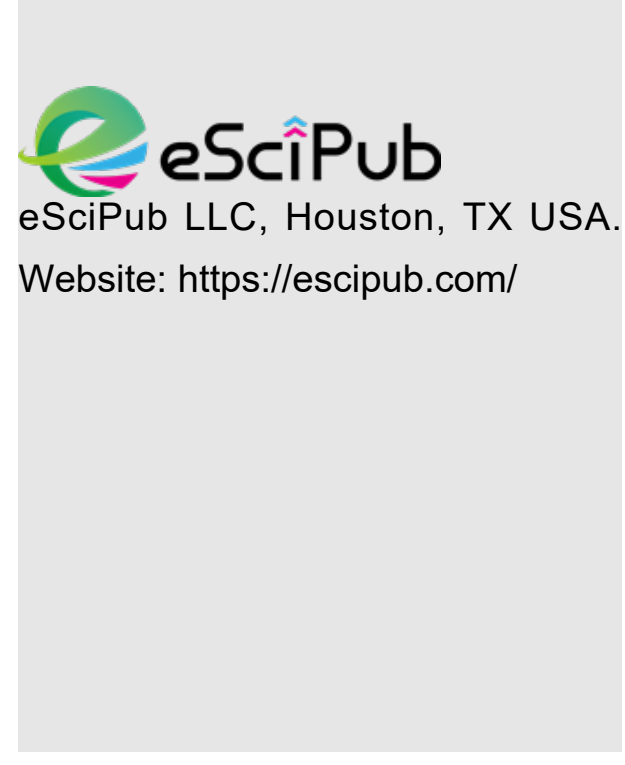


Departmentalization in elementary schools: Contradictions teachers confront

In a paper by Chan and Jarman (2004), departmentalization is described as a educational organizational system where "teachers teach in their area of specialization and students move from one classroom to another for instruction" ( $p$. 70). Departmentalization, while traditional in middle schools and high schools seems to be appearing more frequently these days in elementary schools, even in the primary grade organizational patterns. However, the effects of departmentalized and self-contained organizational structures in the elementary grades on student reading achievement have been debated for over a century (Gumplowicz, 1899). While there has been much discussion of the merits of these organizational patterns, relatively few studies have compared the achievement of elementary school students in self-contained versus departmentalized systems and in those studies no clear pattern of advantage exists ( $\mathrm{Na}$ tional Education Association, 1966). While research has sometimes focused on the relative advantages of these organizational patterns on student achievement (e.g., Broadhead, 1960; Slavin, 1988), more often students' social adjustment has been studied. However, Slavin (1988) also noted that, "There is very little research on departmentalization. However, that which does exist fails to support the practice." (p. 72) His summary of the research on departmentalization of instruction in elementary schools found that this organizational pattern either had no effect or had a negative effect of student achievement. Cattell (1948) was among the first to posit theories concerning the effects of groups upon individuals and vice versa. He summarized the interest of researchers in his era when he wrote "there is no denial that the mind of the group is fashioned by individuals and the group, in turn, fashions the individual mind" (Cattell, 1948, p. 53). It was also during the late 1940 s and early 1950 s that more varied grouping patterns in elementary education began to grow in prominence. As expansion of different sorts of grouping occurred, many schools turned to departmentalization. They did so to equalize class sizes, facilitate multilevel instruction in reading, and redistribute staff talents, and make better use of school buildings, and instructional resources (Raze, 1985).

Potential Benefits of Departmentalized Organizational Systems. Many have argued that there is a positive value in the use of well-qualified teachers in terms of student academic growth (Nye, Konstantopoulos \& Hedges, 2004). This emphasis on high quality teaching arose partly as a result of the knowledge explosion since 1950s and the need for self-contained classroom teachers to learn and "disseminate" complex information especially in the areas of science, current events, and technology. More than 40 years ago Anderson (1962) stated, "only an extraordinary individual--a Leonardo da Vinci--could have an expert knowledge of all of these areas" ( $p$. 254). He supported his claim with research that suggested that only four of 260 teachers considered themselves to be well prepared in all the subjects that they were required to teach. Thus, Howard (1969) concluded, "We can't possibly know enough about everything to teach what is expected... specialization seems like an answer." (p. 551) The hypothesis was that the greater the teacher's understanding of the subject matter, the greater the probability that excellent instruction would occur (Drees, 1989).

Beyond the potential benefits that departmentalization might provide in terms of student achievement, there is some evidence that such an organizational scheme has positive effects on the teachers involved. For instance, in a study of the perceptions of 12 primary grade classroom teachers who experienced a departmentalized instructional plan (Strohl, Schmertzing, Schmerrtzing, \& Hsiao, 2014), these teachers reported feeling less job-related stress as a result of the shift to the departmental organizational plan for teaching. However, whether the stress reduction was related to a reduced sense of personal accountability for student achievement was not explored, but seems one possible basis for the reported reduction in job related stress.

Benefits of Self-Contained Organizational Syst-

AJERR: https://escipub.com/american-journal-of-educational-research-and-reviews/ 
ems. Many educators who support self-contained classrooms contend that instruction at the elementary level should be child-centered rather than subject-centered. They maintain that a selfcontained structure enables teachers and students to develop more in-depth, intimate knowledge of each other. The advantages for teachers knowing each student's strengths and weaknesses have been documented in several studies (for a review, see Barr \& Dreeben, 199I). Continuing along this same line of reasoning, Culyer (1984) hypothesized that increasing the number of educators who interact with a child reduces any single teacher's sense of responsibility for the learning of individual students and that "when two or more teachers help children acquire competency in separate rooms, they will tend to operate in isolation from each other" ( $p$. 418). Others argue that working with only a single teacher all day may provide students a sense of security that may not be possible when students work with many teachers every day.

Oddly enough, this same argument has been used to rally favor for departmentalization. Anderson (1962; Anderson \& Pavin, 1993) was one of the early proponents of this position and argued the case succinctly,

"Perhaps the most significant sense of knowing the child is understanding him in relation to his educational development. It is at this important level that the competent specialist teacher has a big advantage over his generalist counterpart. The teacher who has mastery of an area of knowledge has a frame of reference for evaluating the child's development. He can interpret the child as he is now in terms of how he should be when his schooling is complete" (p. 259).

Gayer (1961) reasoned further,

"it is even possible that there is more likelihood for an introverted child to find rapport when there are several teaching personalities from which to choose "(p. 23).

Such reasoning was supported by the position that even the best teachers may have difficulty relating to some of their students,

"No teacher---no matter how wise, mature, and emotionally suited for teaching---gets along with all pupils" (Anderson, 1962, p. 255).

To date, empirical evidence to support the hypothesis that significantly greater positive student-teacher rapport will result from either a selfcontained or a departmentalized organizational structure, when both are compared to each other, does not seem to exist.

Those who favor self-contained classrooms further contend that this type of organization reduces the time required to organize children for different lessons across the day, maximizing students' time on task (Culyer, 1984; Ward, 1988). Conversely, those who support departmentalization believe that their approach creates greater continuity in the curriculum within and between grade levels, and presents more comprehensive and effective learning experiences because teachers prepare for fewer content discipline lessons. Some who are benevolent on this issue, claim "Good teachers are effective regardless of organization" (Gibb \& Matala, 1962, p. 580).

Changes in Prevalence throughout History. Gibb and Matala (1962) studied the results of several surveys conducted from 1900-1950 and found great fluctuations in the proportion of departmentalized verses self-contained organizational systems used during the first-half of the twentieth century. During this period, when new curricular materials were adopted in specific elementary schools, principals often switched from a self-contained to a departmentalized system to decrease the additional demands imposed on teachers, so that only a few (those who would teach a specific subject) would have to learn the new curriculum (Dees, 1989). Barnes (1961) indicated that 44 percent of the elementary schools in his national sample used departmentalization for at least one subject during the 1959 -1960 school year. In the same year, Robinson (I961) reported that 70 percent of elementary principals preferred a self-contained structure compared to 30 percent who endorsed a departmentalized plan (but only seven percent of these principals endorsing departmentalization below grade four). 
Twenty-six years later, Rodger and Palardy (1987) reported the percentages of elementary schools using departmentalized settings increased dramatically from fourth-grade on, with $25 \%$ of the students in departmentalized schools at the fourth-grade level, $37 \%$ of the students in departmentalized schools at the fifth-grade level, and $52 \%$ of the students in departmentalized schools in sixth-grade classes. That same year, after a comprehensive review of practices nationwide, McPartland, Coldiron, and Braddock (1987) recommended that educators no longer view elementary school grouping structure as an either/or situation. Rather, they found that fewer schools (than in the 1960s) could be classified as completely "student oriented" on one end (fully self-contained) or totally "subject oriented" (fully departmentalized) on the other. It was their recommendation that instructional organization be conceived as a continuum that allows for the integration of numerous organizational structures, based on specific context-bound, studentbased, and philosophical-oriented variables. But, the tough question is: How are these decisions to be determined?

Drees (1989) reported that five distinct types of self-contained and departmentalized organizational systems were widely used (i.e. fully selfcontained, partial self-contained ( 3 or fewer different teachers per day per pupil), semi-departmentalization (one-half to three-fourths of the school day was spent in departmentalized patterns, total departmentalization, and team teaching). Such variations were credited to educators' need to respond to increased student diversity in single elementary school buildings. Drees (1989) also reported that the greatest variability in the use of numerous types of systems for organizing instructional lessons occurs at the fourth and fifth grade levels.

There seems to have been little research on the issue of departmentalization in the past twentyfive years. Nonetheless, our research in fourthgrade classrooms in five states (Allington \& Johnston, 2002; Gabriel, Pereira \& Allington (2011) indicates that some schools remain committed to the use of self-contained classes, while other make extensive use of departmentalization. Why is this so? What can we do to better understand how teachers understand the two organizational plans? What sorts of advantages, if any, does either plan offer teachers or their students?

\section{Methodology}

We studied 28 fourth grade classroom teachers in five states (CA, NH, NJ, NY, TX). Each of these teachers were participants in a national study of exemplary teaching. That is, these 4th grade teachers had been nominated as providing exemplary 4th grade classroom instruction. (for further details on study design and methodology, see Allington, Johnston \& Day, 2002, Allington \& Johnston, 2002). The organizational structure of fourth grade teaching varied across the sites although there seemed to be distinct trends in individual states (with TX elementary schools most likely to departmentalize and those in $\mathrm{NH}$ least likely). However, none of the teachers offered truly "self-contained" instruction. That is, all teachers had their children taught some subjects by another teacher (e.g. art, music, physical education).

We labeled the organizational plan "self-contained" (SC) when the classroom teacher had the sole or primary responsibility for providing core content instruction (reading, language arts, math, science/health and social studies). We labeled the organizational plan as "departmentalized" (DP) when the classroom teacher regularly shared the core content subject teaching responsibilities with at least one other teacher. For instance, some of the organizational plans had our target teacher teaching science to two groups of children with one group being children from some other classroom. In such cases the other classroom teacher then typically had the responsibility to teach two groups of children some other content (e.g. mathematics). But some organizational plans had our target teachers teaching as many as three or four other groups of children each day. In such cases, our target teacher might teach language arts to 4 groups of students while other teachers taught the children who began their school day in her 
classroom their math, science, and social studies lessons.

\section{Method}

Observational data. Each of the classrooms was observed for approximately 10 full instructional days during a single school year. Classroom observers took detailed field notes on classroom activities and, on some days, at the end of the day, completed both a structured Daily Summary where they responded in writing to broad questions about the instruction observed (What were the unique aspects of this teacher's teaching?) and a Likert-like Observation Summary rating of 8 features of the instruction observed (To what extent was the teacher's talk process oriented?) and a 15 item Instructional Dimensions Scale.

\section{Findings}

Daily Summary. Generally, we found the SC and DP classrooms more alike than different. Both groups of teachers were reported to have student-centered classrooms and as exhibiting positive attitudes toward their students. Both provided students choice in the work assignments. That is, all students did not always complete the same assignments but, rather, often had to elect or create the assignment they would complete, especially with the longer-term assignments and projects.

Most teachers communicated clear expectations for both behavioral and academic expectations. Students were given a great deal of autonomy; they were expected to work together and to monitor their own work progress. Both groups of teachers created engaging and respectful work environments. Students were expected to treat each other and the teacher with respect and the teachers modeled this respect in their interactions with students. The summary for one observation included,

"She welcomes their comments and opinions even when they are different from her own and those offered by other students. She often positions herself at the child's eye level when talking or listening to individuals \{e.g., kneels down, sits next to). She expects students (and herself) to listen when one student has the floor."
Both SC and DP teachers incorporated a variety of instructional strategies for fostering learning and literacy development. Few relied on a "single-source curriculum" for any of their instruction. In other words, we observed teachers who used a commercial reading anthology, and a core trade book, or used self-selected trade books and magazines and lots of other curriculum materials in their reading/language arts instruction. We observed teachers who used a social studies textbook, core trade books related to social studies topics, and student self-selected reading of trade books and reference materials for projects. In fact, the use of longer-term assignments, often collaborative in nature, and often integrative, were common in both the $\mathrm{SC}$ and DP classrooms of these exemplary fourth-grade teachers.

Our classroom observations did reveal differences between the SC and DP classrooms as well. The SC classrooms were reported to better organized than the DP classrooms, with smoother transitions across the day that resulted in more effective use of classroom time. This is not surprising given the typical movement of students and/or teachers from classroom to classroom in the DP sites. The transition from one locale to another simply took more time and offered the potential for more organizational difficulties.

In addition, the SC students were more likely to be expected to self-regulate their activities. That is, these students more often were assigned open writing activities while the DP students were assigned more structured writing assignments. It was more likely for the SC students, for instance, to manage literature circles themselves, while the teachers regularly managed discussions in the DP classrooms.

Observers also more often noted SC teachers responding to student interests and questions as they taught. In fact, a unique characteristic of the SC teachers more often noted was their "listening to students". As one observer noted,

"She willingly adjusts her [instructional] goals to account for 'teachable moments'..."

Another observer noted that, 
"Student opinion and ideas seemed to matter. The kids were respectful of each other..."

The key differences reported in the daily observation summaries suggested that, perhaps, the proponents who argue for the potential childcentered benefits of SC organization are correct. Increased reports of an emphasis on self-regulation, of responding to children's interests, and of listening to students as they talked in SC classrooms all support such advocacy.

Observation Summary. In their end of day evaluations of the literacy lessons observed, observers' rating of the classroom lessons produced difference on several features. For instance, the SC classrooms were reported more often using a wide range of materials (73\% of SC v $55 \%$ of DP classrooms) and the SC classrooms produced more unprompted discussion of books being read by the students than the DP classrooms (29\% v. $17 \%)$. In addition, twice as many SC classrooms engaged children in collaborative work over for more than half the day (22\% v. 10\%). But the DP classrooms were rated as having more process-oriented talk (76\% v. $96 \%$ ) across the day. However, on most items there were no patterns of differences in the classrooms reflected in the two organizational schemes.

Instructional Dimensions Scale (IDS). Only 4 items on the IDS were rated even modestly differently by the observers. Observers noted more student collaborative work (2.84 v. 2.58) and smoother transitions (2.85 v.2.66) in SC classrooms. The DP classrooms were rated as making more frequent use of seatwork (2.71 v. 2.58) and greater use of commercial instructional materials (2.82 v. 2.61).

Student reading logs. The students in the SC classrooms reported reading more titles than those in the DP classrooms (149 v. 106) and students in the SC reported more titles read to them by their teachers (12 v. 2).

Reading achievement. Scores of students on a standardized reading achievement test did not differ by the organizational plan (end of year NCEs did not differ, $\mathrm{SC}=49.9 \vee \mathrm{DP}=50.0$ )
Summary. Our observational data produced no clear pattern of substantive advantages for either organizational scheme except, perhaps, in the management area. The DP organization created greater potential for transition problems and the observers noted the larger loss of academic instructional time under the DP scheme. The observational data do suggest that there may be an advantage for the SC organizational framework in fostering collaborative work and self-regulation among students. There was also some evidence that the SC teachers were more childcentered and that they were more likely to use multiple materials while relying less on commercial textbooks and the traditional seatwork activities that accompany most commercial textbooks. Perhaps because of this latter factor, the SC students also reported reading more trade books during the year and their teachers read more titles to them. But none of this seemed to impact the achievement data that indicated no advantages for one organizational plan over the other. All this suggests that Gibb and Matala (1962) may have been right in asserting that effective teachers can be effective regardless of the organizational plan.

However, as noted below, in the teacher interviews it became clear that the DP scheme meant that teachers would see many more children each day for shorter periods of time and this added complexity to the process of dealing socially and instructionally with individual students. The evidence available hints at this instructional complexity but suggests little effect on reading achievement as measured on a standardized test. Nonetheless, during the interviews the teachers discussed other potential impacts of departmentalization.

Interviews. Each of the teachers was asked about personal experiences with departmentalization and about what they saw as the experienced or potential advantages and disadvantages of such an organizational plan. The interviews were audio-tape recorded and transcribed for analysis. The transcripts were then read and coded for content. From the content codes we identified several emerging themes in 
the interview data. The final analytic move involved collapsing emerging themes into the eight dominant themes discussed below.

Because it's just one less subject you have to prep for. This theme dominated the interviews. Teachers who were proponents of departmentalization routinely cited reduced preparation as a primary advantage of departmentalization.

And we do the switch. I did it mainly for selfish reasons. At the time I had just had a baby and it was a management thing. There was one less subject to have to plan for. (WW-NH)

Because it's just one less subject area you have to prep for. (KK-CA)

Departmentalizing? Ah, you're just narrowing it down. You do lesson plans for only that subject, you know, you just go in and teach." (EE-TX)

The teachers liked that we didn't have to plan for so much, but the kids didn't like the switching. (MM-TX)

Even teachers who opposed departmentalization cited the reduction in planning as a potential advantage.

A lot of people just thought it (departmentalization) was easier. They only had to plan for one thing. (SS-NY)

I'm always amazed when I talk with fourth grade teachers from our other buildings. Lots of them are doing departmentalization. I keep asking, "O.K. What are the advantages?" And pretty much what I get from those teachers is "less preparation." (PP-TX)

In the self-contained [classroom] you have ten thousand lesson plans you are trying to do and all these books and you cannot be an expert on everything. (BB-TX)

Just to teach what I enjoy teaching or do what I'm interested in and good at. A second popular theme that emerged in the interviews was that departmentalization allowed teachers to focus their energies on curriculum areas they were interested in or felt better prepared to teach.

If a teacher has a deep love for science, then let them go for it. Let them teach your kids. (KK$\mathrm{CA})$

Wouldn't it be great just to teach math and science, let's say two times in the mornings and not have to deal with language arts...I just do what I enjoy and what I know is productive. Do it two times in the morning...That was attractive. JJCA)

l'd love to do that though. l'd love to focus on a just couple of different subjects and really fine tune them. (SS-NH)

I'd love to do science. I keep thinking about that. If someone else would take over social studies.... (DD-NY)

But there are times that I think it would be great because I could choose something that I really love to do and do that really well. (AA-TX) I love teaching science. So, in that respect it's very nice. You're planning for the one subject science - and you know, I can turn them on to science. (SS-NY)

I can get really excited about science and she can get really excited about social studies and I think the kids get the best of it. (HH-NY)

He really didn't feel competent with teaching language arts but felt really confident with math and science... (JJ-CA)

It gets them prepared for junior high. Compared to the teacher benefits discussed, far fewer teachers offered advantages that might accrue to children from experiencing a departmentalized curriculum. In fact, it was the issue of the impacts of departmentalization on children that the teachers often identified as a flashpoint in faculty discussions of departmentalization.

I think it benefits kids too... It would be great if we did it more... To get those kids ready for junior high. (KK-CA)

As far as fourth graders go, it is difficult for them... l've had parents disagree with it at the fourth-grade level. (SS-CA)

I will be honest. I thought it [departmentalization] was awful. This is all based on personal experience... Fourth graders were entirely too young to go from one class to another. (RR-NY)

There is a lot of value in getting homogeneous groups together. But, I don't know whether it is good in the long run. I don't like seeing anyone develop an attitude that they are smarter than other people. (EE-NY) 
You know, you see a million kids a day and, I don't know, I just don't think you get the relationships built with all those kids (MM-TX)

You can't integrate as much if its separate, you know. Both groups of teachers voiced concerns about the impact of departmentalization on curriculum integration. While there was some discussion of the necessity of team planning and shared visions of what optimal teaching and learning looked like, there was also candid discussion of just how often departmentalization led to a loss of curriculum integration and instructional coherence.

I guess I would be afraid it wouldn't be as continuous. Like, I wouldn't be able to say, "Remember what you did in science? Well, now you need to write about such and such..." I wouldn't be able to say that because someone else would have taught science and I wasn't there. (SS-NH) You really have to be self-contained for the children to make connections all day long. (SS-NY) I just never did that [departmentalize]. I just told them I didn't want to... If there is something that I can do with social studies during math and science I want to be able to hit it right then. $(\mathrm{HH}-$ $\mathrm{NH})$

It [departmentalization] just created so many problems. I guess I mean less integration among the subject areas. In other words, not social studies and science in their boxes... I just felt that they were taking my kids away from me too much to be able to do all I wanted to do with them. (RR-NY)

I was really doing separate language arts... and then I'd do social studies when they came back ... I think integrating is the hardest part of departmentalization. (BB-TX)

I want to be self-contained next year. Because when I'm teaching literature, when we're doing Tolliver's Secret, we're teaching social studies too. I can't see breaking apart in the afternoons like we've been doing... It [the curriculum] just shouldn't be broken apart like it's been broken up. (SS-NY)

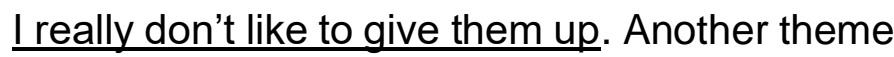
that ran across the interviews with both groups of teachers was the "ownership and relationship" issue. These teachers talked about how much they liked having a single group of children that they knew really well, all day long. Even many of the teachers currently working in departmentalized structures mentioned the "ownership/relationship" issue as a positive feature of self-contained classrooms.

I really love having my children with me all day long (QQ-NY)

I don't know if l'd be interested in it [departmentalization]. Sometimes I feel like I would lose a lot of what I do. I really like having the same kids all day long. (DD-TX)

There are things I miss [with departmentalized structure]... like just being able to, just having your own class for a whole day, versus giving up ownership of your group. (WW-NH)

They'd ask, "Why can't we just stay with you all day?" And his kids wanted to stay with him all day. And I didn't like to lose my class... I preferred my homeroom kids over anybody last year. (EE-TX)

There is a lot I like about keeping my kids all day... I really like the relationship with kids... Because I know my own kids so well. And they know me. So, if I had to, I'd go to a more selfcontained structure than a more departmentalized structure. (PP-TX)

I can't teach on tight schedule. A number of the teachers working in self-contained classrooms noted another problem that departmentalization presented them - fitting instruction into a fixed schedule.

That's definitely one of the hard things. It's like we're on a roll, we'll just keep going... But if you're getting someone else's kids, you're going to stop whatever lesson you are doing because there is someone else coming in. (DD-NH)

I think maybe it is my interest in integrating... Pulling this in... Doing this and then that... You are just so limited by time constraints [when departmentalized]. (RR-NY)

I don't think social studies should be taught in a forty-minute period. I think it should be whenever it is relevant. (KK-NH) 
I just didn't want to do it [departmentalize]... I am not one who likes to be confined to a time slot. (DD-NY)

I really love having my class with me all day. It helps to have a lot more flexible time when you're not so dictated by the class [schedules]... I like the flexible schedule where I can spend more time and do a better job integrating subjects within subject areas. (QQ-NY)

[With departmentalization] you're rushed... On some days you could spend more time on one subject than others [in a self-contained classroom] but here (in a departmentalized school) you're da, da, da, you go in, you teach, you get out... You're limited on time. (EE-TX)

The problem would be scheduling: "My door is a revolving door". Another concern voiced by many teachers, both those working in departmentalized and those in self-contained classrooms, was the fragmentation of the school day and the curricular experiences of children. These teachers typically reported that their days were already chopped into too many segments and that departmentalization simply added to this fragmentation.

It gets almost impossible to switch three ways with the scheduling for resource room, remediation, gym, music, and art. So, I teach a completely self-contained class. (RR-NY)

We do have a problem. We have lots of special programs and it just seems a rarity that I have all of my children in the room at the same time...

(AA-TX)

The scheduling would be a nightmare. My problem right now is scheduling. It's just not constant every day. I have so many special need kids that my door is a revolving door. (EE-NY)

Parents are hard to please. The teachers also talked about administrators and their roles in the decisions about grade-level organization. Three distinct patterns were presented: "teachers know-best", self-contained preference, and departmentalized preference. Within the latter category, there were several references to using departmentalization as a strategy to avoid dealing with parental preferences for particular teachers (or parental concerns about particular teachers).

The principal kind of leaves that [departmentalization decisions] for us to do... It depends on how many students... Like we have three teachers in fourth grade and five in third, so it's going to change somehow next year. (BB-TX)

We've talked about it [departmentalization] at different times, at least for science and social studies, but the administration hasn't wanted us to do it. (AA-NH)

Our principal... He did not like at all... His opinion was that departmentalization was not appropriate for elementary school ages. That they get it soon enough when they go off to middle school. (KK-TX)

Basically this [departmentalization] is done because our principal wants the children to have exposure to all three teachers... it's hard because I know parents [who say], "Well, why can't my son have this teacher" You can only give each teacher twenty or so children. So, I think this [departmentalization] appeases everyone. I think that is where we are at right now. (SS-NY) Summary. In these interviews we found three categories of beliefs about the SC and DP organizational schemes. Some teachers were strong SC proponents and literally refused to even consider other options. Some teachers were proponents of DP and their support for the DP plan focused heavily on two factors: a) fewer lesson preparations, and b) teacher interest/expertise. But many of these teachers, regardless of the organizational structure they were now working in, offered us an "it just depends" stance. They articulated potential benefits and limitations but usually noted that how well DP would work depended heavily on who was involved.

At the heart of the matter, however, was an underlying concern about whether a DP plan was good for children. As several respondents noted, the DP plan seemed to benefit teachers more than children, except preparation for future schooling. In fact, few teachers mentioned any specific benefits of a DP plan that would benefit children. At the same time, several teachers 
voiced their concerns that students "got lost in the shuffle' of departmentalized schedules. But the opportunity to focus lesson planning and, especially, to focus on teaching the subject one really enjoyed and was expert in was also seen as having a potential benefit to children through improved instruction.

\section{Confronting contradictions and complexities}

Analyses of the observational summaries portrayed many more commonalities among these fourth-grade teachers than differences, even though these teachers offered instruction under different organizational schemes. Likewise, the achievement test comparison also indicated no advantage for one organizing scheme over the other. However, our analyses of the teacher interviews indicate several cross currents running through those data. First, the teachers seemed to view departmentalization as providing major benefits to teachers and, perhaps, provided a sympathetic strategy for dealing with a difficult organizational issue - parental preferences for certain teachers. Departmentalization was most often viewed as reducing the complexity of elementary school teaching and perhaps reducing the workload as well. These findings parallel those of Strohl, et al (2014).

At the same time, there were fewer benefits mentioned for students under either organizational scheme. Preparation of these fourth graders for middle school/junior high, where departmentalization is an almost standard feature, was a common benefit offered by some for departmentalizing. But others argued quite vigorously against viewing this as a benefit, even given the dominant departmental organization of middle schools and junior high schools. Providing students with a teacher who was, perhaps, better prepared to teach a specific subject, and was, possibly, more interested in that subject, and therefore, perhaps, more enthusiastic about the subject was another potential benefit offered for students. A third response suggested that departmentalization was, at least in some schools, an organizational structure designed to limit any one child's exposure to a teacher considered less than optimally effective by parents. Thus, the school, or at least the site administrator, benefited by producing a higher level of parent satisfaction when instruction was departmentalized. One could argue a benefit for some children - those children who were not now seated all day in a self-contained classroom headed by a classroom teacher considered ineffective by their parents.

All in all though, one is left with a distinct impression that there seem more obvious adult and organizational benefits than student benefits in the practical arguments offered for departmentalization. Other teachers argued that the more engaging instruction that departmentalization might offer also increased likelihood of the fragmentation of the curriculum and the loss of instructional time in the lengthier transition periods that accompany departmentalization. In addition, many of these exemplary teachers were concerned about the "tyranny of the clock" that accompanied departmentalization. Most were working in schools where the instructional day was already far more segmented than desired with special subject classes, special education and remediation schedules, and student assemblies, performances, and an assortment of other events and structures that segmented the day in numerous short segments for actually teaching. Many teachers viewed departmentalization as simply adding to an already too segmented day.

\section{Conclusion}

This study of the responses of exemplary fourthgrade teachers does little to clarify the longstanding debate about the costs/benefits of selfcontained or departmental organizational plans in the upper-elementary grades. While we identified several differences in the instruction offered in the two organizational models, there were no differences in student achievement between them. Instead, the primary finding of this effort is the layered complexity of the question of costs and benefits. For instance, exemplary teachers told us about the potential benefits of departmentalization plans for reducing the complexity of the teaching task, but when discussing students, they more often addressed the costs associated with departmentalizing instruction, 
particularly the potential loss of close connections with their students. These fourth-grade teachers also commonly noted that departmentalization was a strategy for ensuring that all students were exposed to multiple teachers, an outcome that they felt undermined parental objections/preferences for particular teachers. Departmentalization, then, was viewed by these teachers as simplifying the roles the school administrator had to play.

These interviews with exemplary fourth-grade teachers simply mirrored, in many respects, the historical controversies surrounding the debate about self-contained and departmentalized organizational plans for elementary schools. These exemplary teachers voiced the same preferences and concerns that earlier investigations have noted. What remains lacking is any large-scale experimental evaluation of the effects of departmentalization on various aspects of student development and student academic achievement.

Endnote: The author would like to thank the following people for their assistance in the project: the classroom teachers who allowed us to study their teaching practices, and the other researchers on the project, including Kim Boothroyd, Cathy Collins Block, Greg Brooks, Melissa Cedeno, Jeni Pollack Day, Gay Ivey, Haley Woodside-Jiron, Peter Johnston, Lesley Morrow, Jean Veltema, and Ruth Wharton-McDonald. The paper is based on research supported in part under Research and Development Centers Program (award number R305A6005) as administered by the Office of Educational Research and Improvement, U.S. Department of Education. However, the contents do not necessarily represent the positions or policies of the sponsor.

\section{References}

[1] Allington, R. L. (2002). What l've learned about effective reading instruction from a decade of studying exemplary elementary classroom teachers. Phi Delta Kappan, 83(10), 740-747.

[2] Allington, R. L., \& Johnston, P. H. (Eds.). (2002). Reading to learn: Lessons from exemplary 4th grade classrooms. New York: Guilford.

[3] Allington, R. L., Johnston, P. H., \& Day, J. P.
(2002). Exemplary fourth-grade teachers. Language Arts, 79(6), 462-466.

[4] Anderson, R. (1962). The case for teacher specialization in the elementary school. The Elementary School Journal, 63, 253-260.

[5] Anderson, R., \& Pavin, B. (1993). Nongradedness: Helping it to happen. Lancaster, PA: Technomic.

[6] Barnes, R. (1961). Survey of status and trends in departmentalization in city elementary schools. Journal of Educational Research, 55, 291-297.

[7] Barr, R. \& Dreeben, R. (199l). Grouping students for reading instruction. In Barr, R., Kamil, M., Mosenthal, J., Pearson, P. D. (Eds.). Handbook of reading research, Volume II. White Plains, NY: Longman, pp. 885-911.

[8] Broadhead, F. (1960). Pupil achievement in semi-departmental elementary/junior high schools. The Elementary School Journal, 61, 385-390.

[9] Burns, R. \& Mason, D. (1998). Class formation and composition in elementary schools, American Educational Research Journal, 35(4), 739772.

[10] Cattell, R. (1948). Concepts and methods in the measurement of group syntality. Psychological Review, 55, 48-63.

[11] Chan C. T., \& Jarman, D. (2004). Departmentalize elementary schools. Principal, 84(1), 70-72.

[12] Culyer, R. (1984). The case for the self-contained classroom. Clearing House, 57 417-419.

[13] Drees, J. (1989). Elementary school organization: Self-contained and departmentalized classroom structures. Des Moines, IO: Des Moines Public Schools.

[14] Gabriel, R., Pereira, J. D., \& Allington, R. L. (2011). What effective teachers taught us about learning to teach effectively. In I. M. Saleh \& M. Swehine (Eds.), Teaching teachers: Approaches in improving quality of education (pp. 343-357). Happague, NY: Nova Science Publishers.

[15] Gayer, N. (1961). The myth of the self-contained classroom. California Teachers Association Journal, 13, 22-26.

[16] Gibb, E. \& Matala, D. (1962). Study on the use of special teachers of science and mathematics in Grades 5 and 6 . School Science and Mathematics, 62, 565-585.

[17] Gumplowicz, L. (1899). Outlines of sociology (trans. by F. H. Moore.) Philadelphia: American Academy of Political and Social Science.

[18] Howard, E. (1969). A look at specialization, Educational Leadership, 26, 547-556.

[19] McPartland, J. M., Coldiron, J. R., \& Braddock, J. H. (1987). School structures and classroom practices in elementary, middle, and secondary 
schools. Baltimore, MD: Center for Research on Elementary and Middle Schools, Johns Hopkins University.

[20] National Education Association. (1966). Departmentalization in elementary schools. NEA Research Bulletin, 44, 27-38.

[21] Nye, B., Konstantopoulos, S., \& Hedges, L. V. (2004). How large are teacher effects? Educational Evaluation and Policy Analysis, 26(3), 237-257.

[22] Raze, N. (1985). Primary and intermediate grade configurations: A review of the literature. Redwood City, CA: San Mateo County Office of Education.

[23] Robinson, H. M. (1961). Summary of investigations relating to reading, July 1,1959 to June 30 , 1960. Journal of Educational Research, 54, 203220.

[24] Rodger, M. \& Palardy, J. (1987). A survey of organizational patterns and grouping strategies used in elementary schools in the Southeast. Education, 108, 113-118.

[25] Slavin, R. E. (1988). Synthesis of research on grouping in elementary and secondary schools. Educational Leadership, 46(1), 67- 77.

[26] Strohl, A., Schmertzing, L., Schmertzing, R., \& Hsiao, E. (2014). Comparison of self-contained and departmentalized elementary teachers' perceptions of classroom structure and job satisfaction. Journal of Studies in Education, 4(1), 109127.

[27] Ward, R. (1988). Toward improved school organization: Further look at horizontal structure. National Elementary Principal, 22, 93-115. 